\title{
Factors Associated with Missed and Cancelled Appointments in the Endoscopy Unit: Descriptive Study
}

Reema Alnasser ${ }^{1}$, Saad Alkhowaiter ${ }^{2,3}$, Sarah Alhusaini ${ }^{3}$, Badr Aljarallah ${ }^{4}$

1. Medicine, King Saud Univerisity, Riyadh, SAU 2. Gastroenterology, King Khalid University Hospital, Riyadh, SAU 3. Medicine, King Saud University, Riyadh, SAU 4. Hepatology and Gastroenterology, Qassim University Medical City, Qassim, SAU

Corresponding author: Saad Alkhowaiter, s.alkhowaiter@gmail.com

\section{Abstract}

\section{Background and aim}

Canceled and missed appointments at the endoscopy unit affect the quality of the provided services and can negatively impact patient outcomes. Assessing the association between the various factors relating to nonattendance will show whether the defective aspects are organizational or personal, which is essential to improve the quality of the healthcare system. Moreover, this study will be of value in our region due to the current scarcity of studies in the Middle East.

\section{Methods}

A descriptive study was conducted at King Khaled University Hospital in Riyadh, Saudi Arabia. A database of participants was established from those who missed/canceled their outpatient endoscopy clinic appointment; purposive sampling was applied, excluding those who are under 14 years old. Demographic data and organizational factors (e.g., referred clinic and the lead time) were collected from the patients' files and a structured interview done by phone within 7-14 days of the missed/canceled appointment.

\section{Results}

A total of 919 endoscopy procedures were scheduled in an eight-week period, and 179 procedures were missed/canceled (19.48\%); 84\% were missed, and $16 \%$ were canceled. The highest percentage of the population had a high-school diploma or less. The results showed that roughly half of the patients were unemployed. More than two-thirds of the patients had undergone an endoscopy within the past year or less. The majority stated that they underwent the procedure in a different facility, which might be due to various reasons, one of which could be justified as long lead time.

\section{Conclusion}

Received 01/30/2020 Review began 03/02/2020 Review ended 03/07/2020 Published 03/14/2020

(c) Copyright 2020 Alnasser et al. This is an open access article distributed under the terms of the Creative Commons Attribution License CC-BY 4.0., which permits unrestricted use, distribution, and reproduction in any medium, provided the original author and source are credited.
An annual update of patients' files is suggested. Text messages can help serve as a reminder in addition to clear appointment instructions that will aid in minimizing the absence rates. Overbooking is recommended to decrease the lead time and increase clinic efficiency. Raising patients' awareness regarding the effect of missing appointments as well as upgrading the communication methods will assist in decreasing the rate of missed appointments.

Categories: Internal Medicine, Gastroenterology, Quality Improvement Keywords: endoscopy, missed, cancelled, nonattendance, appointments

\section{Introduction}

Canceled and missed outpatient endoscopy appointments are an issue faced daily in the endoscopy units globally [1]. It is considered as a challenge since they affect the quality of the provided services and healthcare provider performance, and have a tremendous impact on the patients' waiting time, as well as delaying the diagnosis of many serious conditions. Therefore, it can negatively influence the patient's outcomes [2, 3]. A significant proportion of the missed appointments will be rescheduled eventually, thereby adding a burden to an already loaded waiting list [4]. This is an issue faced by many departments in the medical field but is more significant for colonoscopy clinics due to the high costs of procedures, which is an estimated net loss of $\$ 725$ per day for the average facility [5].

At our facility, patients are referred for endoscopy by their doctor either from the clinic or in an inpatient setting. In the case of the typical outpatient scenario, the patient must present to the unit itself to confirm and book the appointment, at which time the procedure and preparations are explained. A week prior to the appointment, the patient will receive a text reminder. If the patient wants to cancel the appointment, he or she has the option of canceling either through a phone call or by presenting at the unit. 
The unit has about 20 bookings each day. Despite inconsistencies in many patients who attend their appointment at the facility, it is still generally busy, with procedures varying from gastroscopies to colonoscopies for either diagnostic and/or therapeutic reasons.

In this study, our objectives were to detect the prevalence of missed and canceled appointments in addition to identifying the factors that contribute to this problem.

Furthermore, identifying the factors will show where the main defects are, whether they are individual, institutional, or both. Thus, a full understanding of these causes is essential and will provide us with guidance to enhance the quality of the healthcare system by minimizing the waiting and diagnosis time, and it will lead the way to a cost-effective system.

This study will not only benefit the healthcare system but it will also aid in the improvement of many healthcare systems in our region and worldwide.

\section{Materials And Methods \\ Study population and methods}

This was a descriptive study conducted at the King Khaled University Hospital (KKUH) endoscopy clinic, Riyadh, from April 2017 to April 2018. The research ethics committee of KKUH approved the study. Purposive sampling was applied, and a database of participants from 5/2/2017 to 30/3/2017 was composed. All missed and canceled outpatient endoscopy appointments were included.

A questionnaire was constructed based on factors previously studied [1-4]. A pilot study was carried out on a sample of 20 respondents; the questionnaire was modified afterward by integrating essential elements such as lead time and whether or not the patient is still symptomatic. The questionnaire is divided into five sections: (1) demographic data, which covers the basic personal data in addition to estimated drive time to the hospital; (2) past personal/family medical history, focused on the history of colon polyp or cancers in general; (3) organizational factors, including information about the referred clinic and the lead time (time between the referring clinic appointment and the endoscopy appointment), as well as the SMS reminder and the method of the explaining of the procedure; (4) personal factors, including questions about the reason for the procedure and if the patient is symptomatic. The most important question is the main reason for missing/canceling the appointment, which is categorized as a personal factor, such as a health-related issue, social matter, transportation, fear/anxiety, neglect/forgetfulness, or an organizational factor, such as a long waiting list or miscommunication. Finally, we incorporated a suggestion section to team up with the patients to find solutions to this issue.

\section{Data collection and analysis methods}

The data collection process was divided into two steps. First, the demographic data and questions in the section about organizational factors were retrieved from patients' files. Secondly, an 8-10-minute interview with the patient was conducted via phone call within 7-14 days of the missed/canceled appointment. All phone calls were carried out with hospital provided phones to keep the data private and secured. Any unanswered calls within the 14 days were excluded from the data analysis yet included in the prevalence calculations.

Data were analyzed using the Statistical Package for Social Studies (SPSS 22; IBM Corp., Armonk, USA). Categorical variables were expressed as percentages. The rate of nonattendance included all missed and canceled outpatient appointments regardless of the completeness of data.

\section{Results}

A total of 919 endoscopy procedures were scheduled in an eight-week period; 179 procedures were missed/canceled (19.48\%), of which 151 were missed, and 28 were canceled ( $84 \%$ and $16 \%$, respectively). We were able to contact 109 of those patients. Table 1 illustrates the patients' sociodemographic data. Gender was nearly equal ( $55 \%$ female and $45 \%$ male). The majority were married (76.1\%). More than half of the patients (58.7\%) were high school graduates or less. Moreover, $48.6 \%$ were housewives/husbands or retired. Out of the whole population, $25.7 \%$ reported that they live outside the city, which means they have to travel to attend appointments. 


\section{Cureus}

\begin{tabular}{|c|c|c|}
\hline Demographic characteristics & Number & $\%$ \\
\hline \multicolumn{3}{|l|}{ Gender } \\
\hline Female & 60 & 55.0 \\
\hline Male & 49 & 45.0 \\
\hline \multicolumn{3}{|l|}{ Age } \\
\hline$<20$ & 3 & 2.8 \\
\hline 20-34 & 18 & 16.5 \\
\hline $35-44$ & 23 & 21.1 \\
\hline $45-54$ & 26 & 23.8 \\
\hline $55-64$ & 24 & 22.0 \\
\hline$>65$ & 15 & 13.8 \\
\hline \multicolumn{3}{|l|}{ Marital status } \\
\hline Married & 83 & 76.1 \\
\hline Single & 21 & 19.3 \\
\hline Divorced & 2 & 1.8 \\
\hline Widowed & 3 & 2.8 \\
\hline \multicolumn{3}{|l|}{ Education } \\
\hline High school graduate or less & 64 & 58.7 \\
\hline Higher education & 45 & 41.3 \\
\hline \multicolumn{3}{|l|}{ Occupation } \\
\hline Employee & 41 & 37.6 \\
\hline Student & 15 & 13.8 \\
\hline Housewife/husband & 30 & 27.5 \\
\hline Retired & 23 & 21.1 \\
\hline \multicolumn{3}{|l|}{ ETA } \\
\hline $10-29 \mathrm{~min}$ & 32 & 29.4 \\
\hline $30-49 \min$ & 35 & 32.1 \\
\hline$>50 \mathrm{~min}$ & 14 & 12.8 \\
\hline Out of Riyadh & 28 & 25.7 \\
\hline
\end{tabular}

\section{TABLE 1: Demographics of the participants}

ETA - estimated time of arrival

Table 2 indicates the past medical history of the patients, as $56.9 \%$ suffered from a chronic illness such as diabetes, hypertension, hypothyroidism, or hyperlipidemia; $7.3 \%$ had mental issues. A few patients had a history of colon polyps and colon cancer (9.1\% and $2.75 \%$, respectively). Endoscopy had in the past $57.8 \%$, and $29.2 \%$ of those had it in the past year or less. 


\section{Cureus}

\begin{tabular}{|c|c|c|}
\hline Past medical history & Number & $\%$ \\
\hline Patient suffering from mental issues & 8 & 7.3 \\
\hline Patient suffering from chronic illnesses & 62 & 56.9 \\
\hline \multicolumn{3}{|l|}{ Personal history } \\
\hline Polyps history & 10 & 9.2 \\
\hline Colon cancer history & 3 & 2.7 \\
\hline \multicolumn{3}{|l|}{ Family history } \\
\hline Polyps & 1 & 0.9 \\
\hline Colon cancer & 5 & 4.6 \\
\hline Family history of any type of cancer & 30 & 27.5 \\
\hline \multicolumn{3}{|l|}{ Previous endoscopy } \\
\hline Underwent endoscopy in the past & 63 & 57.8 \\
\hline \multicolumn{3}{|l|}{ How long ago endoscopy was done } \\
\hline$<3$ months & 8 & 7.3 \\
\hline $3-6$ months & 8 & 7.3 \\
\hline 7 months - 1 year & 16 & 14.6 \\
\hline $2-3$ years & 15 & 13.7 \\
\hline$>3$ years & 16 & 14.6 \\
\hline
\end{tabular}

TABLE 2: Past medical history of those who missed/canceled their appointment

Table 3 demonstrates the organizational factors; $34.9 \%$ of the appointments were a referral from the gastrointestinal clinic, and $23.9 \%$ from the ambulatory. The larger number of appointments were scheduled within four to six weeks of the booking (42.2\%). Out of all respondents, $31.2 \%$ claimed that they did not receive an SMS reminder; $65.1 \%$ said that the procedure was explained to them, mostly a written explanation is given by the receptionist. 


\section{Cureus}

\begin{tabular}{|c|c|c|}
\hline Organizational factors & Number & $\%$ \\
\hline \multicolumn{3}{|l|}{ Referred clinic } \\
\hline Ambulatory & 26 & 23.9 \\
\hline Surgery & 17 & 15.6 \\
\hline Gastrointestinal & 38 & 34.9 \\
\hline Other & 28 & 25.6 \\
\hline \multicolumn{3}{|l|}{ Type of procedure } \\
\hline Gastroscopy & 39 & 35.8 \\
\hline Colonoscopy & 47 & 43.1 \\
\hline Both & 23 & 21.1 \\
\hline \multicolumn{3}{|l|}{ Lead time } \\
\hline$<1$ week & 5 & 4.6 \\
\hline $1-3$ weeks & 21 & 19.3 \\
\hline 4-6 weeks & 46 & 42.2 \\
\hline$>6$ weeks & 37 & 34.0 \\
\hline \multicolumn{3}{|l|}{ Reminder and education } \\
\hline Received an SMS reminder & 75 & 68.8 \\
\hline The procedure was explained & 71 & 65.1 \\
\hline \multicolumn{3}{|c|}{ How the procedure was explained } \\
\hline Verbal & 8 & 7.3 \\
\hline Written & 60 & 55.0 \\
\hline Both & 3 & 2.8 \\
\hline \multicolumn{3}{|l|}{ By whom } \\
\hline Doctor & 3 & 2.8 \\
\hline Receptionist & 68 & 62.3 \\
\hline
\end{tabular}

TABLE 3: Organizational factors of those who missed/canceled their appointment

Table 4 shows the patient's personal factors; $19.3 \%$ of the patients underwent endoscopy due to bleeding along the gastrointestinal tract. Other reasons included abdominal pain (16.5\%), inflammatory bowel diseases (14.7\%), or routine screening for polyps/cancer (11.9\%). Out of all patients, $62.4 \%$ had symptoms upon booking the appointment. However, $17.4 \%$ reported that their symptoms had subsided by the time of the appointment. The colonoscopy preparation was taken by $8.3 \%$ but they did not attend the appointment. Personal reasons for not attending (49.5\%) mainly involved social matters, health-related issues, fear, and neglect. Organizational factors, including miscommunication and long lead time, constituted $15.6 \%$. Appointments were missed due to multifactorial reasons by $16.5 \%$.

\begin{tabular}{|c|c|c|}
\hline Personal factors & Number & $\%$ \\
\hline \multicolumn{3}{|c|}{ Reasons for undergoing endoscopy } \\
\hline Screening & 13 & 11.9 \\
\hline IBD & 16 & 14.7 \\
\hline GI bleed & 21 & 19.3 \\
\hline
\end{tabular}




\section{Cureus}

$\begin{array}{ll}\text { GERD } & 12\end{array}$

Other

Symptom status

Symptomatic at the time of booking the appointment

The symptoms subsided before the appointment

Completed drinking the preparation (if colonoscopy)

Reasons for not drinking the preparation (if colonoscopy)

Could not tolerate it

Decided not to come

Could not retrieve it

Other

Reasons for missing/canceling the appointment

Health-related issue

Social

Fear/anxiety

Neglect/forgetfulness

Miscommunication

Transportation

Long waiting list

Other

More than one of the above

Appointment status

Missed

Canceled

Cancellation method

Attending the clinic

Reasons for not canceling

Busy

Did not know how

Called but no one answered

Rescheduled the appointment

Yes

\section{TABLE 4: Personal factors of those who missed/canceled their appointment}

IBD - inflammatory bowel diseases; GI - gastrointestinal; GERD - gastroesophageal reflux disease 
Only $23.9 \%$ of the patients did cancel, $92 \%$ of whom had to attend the clinic to cancel. The remaining $8 \%$ canceled via phone call. Thirty-three percent did reschedule their appointment.

\section{Discussion}

The rate of nonattendance in the outpatient endoscopy clinic in this study is within the range reported in other studies (14.7\% to $29 \%$ ) [6-9].

A scope of multiple prior studies assessing the nonattendance rates illustrated that in California and North Carolina, the US, a total of 2,157 outpatient procedures were scheduled, from the records for these procedures, 263 nonattendances (12.2\%) were identified [3]. Another study in Valencia, Spain, found similar results, a total of 265 patients (14.7\%) missed their appointment [7].

This study was mainly focused on the personal/organizational factors of nonattendance. The level of education somewhat corresponds with the nonattendance, as $58.7 \%$ were high school graduates or less compared with $41.3 \%$ who had received higher education. The results showed that roughly half of the patients were unemployed. Thus, we can partially exclude the working factor or conflict between the appointment timing and work hours $[2,5]$.

The rate of nonattendance of those who had polyps history was low, which might contribute to the fear of progression of polyps to malignancy. More than two-thirds of the patients had undergone an endoscopy in the past year or less, the majority of which stated that they underwent the procedure at a different facility, which might be justified as long lead time. In a previous study, long lead time was significantly associated with missed appointments $[5,7]$.

Even though the cancellation policy includes both attending the clinic and canceling via phone call, the latter is not actually implemented. Many patients claimed that they called but received no answer. In addition, some patients were unaware of the cancellation policy.

This illustrates that the main defect is a systemic factor that is both organizational and individual. The low rate of cancellation can be attributed to the fact that $92.3 \%$ of those who canceled had to attend the clinic to do so, which was not feasible.

A number of solutions have been suggested to decrease the effect of the problem. Some of which are the application of pre-assessment clinics prior to the endoscopy appointment (in which the patients are provided with detailed verbal and written instructions and given the necessary preparations), enhanced communication, reduce referrals for patients with limited life expectancy and generate a hospital-specific endoscopy video tutorial [1-4]. The pre-assessment clinics have been implicated in one UK center and resulted in a significant decrease in the missed and canceled appointments from $22 \%$ to $3 \%$ [3].

Annual update of patients' files is advised as many files had old/wrong numbers, SMS reminders, in addition to clear instructions about the appointment, and patient's awareness will help in minimizing the absence rates not only in the endoscopy clinic but rather in the facility as a whole $[1,6]$. Overbooking is recommended to decrease the lead time and increase clinic performance $[10,11]$.

There are some limitations to the study. A few of the electronic records of the patients have outdated contact information. Therefore, some of the patients who missed their appointments were not reachable. This resulted in a lack of their data in the questionnaire, although they were included in the prevalence.

\section{Conclusions}

In conclusion, raising patients' awareness regarding the effect of missing appointments and upgrading the communication methods will assist in decreasing the number of missed appointments. We suggest annual update of patients' files. Also, SMS reminders in addition to clear appointment instructions will aid in minimizing the absence rates. Overbooking is recommended to decrease the lead time and increase clinic efficiency.

\section{Additional Information \\ Disclosures}

Human subjects: Consent was obtained by all participants in this study. Animal subjects: All authors have confirmed that this study did not involve animal subjects or tissue. Conflicts of interest: In compliance with the ICMJE uniform disclosure form, all authors declare the following: Payment/services info: All authors have declared that no financial support was received from any organization for the submitted work. Financial relationships: All authors have declared that they have no financial relationships at present or within the previous three years with any organizations that might have an interest in the submitted work. 
Other relationships: All authors have declared that there are no other relationships or activities that could appear to have influenced the submitted work.

\section{References}

1. Chopra D, Hookey LC: Comorbid illness, bowel preparation, and logistical constraints are key reasons for outpatient colonoscopy nonattendance. Can J Gastroenterol Hepatol. 2016, 2016:2179354. $10.1155 / 2016 / 2179354$

2. Partin MR, Gravely A, Gellad ZF, Nugent S, Burgess JF, Shaukat A, Nelson DB: Factors associated with missed and cancelled colonoscopy appointments at veterans health administration facilities. Clin Gastroenterol Hepatol. 2016, 14:259-267. 10.1016/j.cgh.2015.07.051

3. Adams LA, Pawlik J, Forbes GM: Nonattendance at outpatient endoscopy. Endoscopy. 2004, 36:402-404. $10.1055 /$ s-2004-814329

4. Tibble JA, Forgacs I, Bjarnason I, Przemioslo R: The effects of a preassessment clinic on nonattendance rates for day-case colonoscopy. Endoscopy. 2000, 32:963-965. 10.1055/s-2000-9629

5. Berg BP, Murr M, Chermak D, Woodall J, Pignone M, Sandler RS, Denton BT: Estimating the cost of noshows and evaluating the effects of mitigation strategies. Med Decis Making. 2013, 33:976-985. 10.1177/0272989x13478194

6. Kalayjian E, Bringman D, Naughton A, Bond S, Sarver W, Mion LC: Improving adherence to screening colonoscopy preparation and appointments: a multicomponent quality improvement program. Gastroenterol Nurs. 2015, 38:408-416. 10.1097/sga.0000000000000194

7. Sola-vera J, Saez J, Laveda R, et al.: Factors associated with non-attendance at outpatient endoscopy . Scand J Gastroenterol. 2008, 43:202-206. 10.1080/00365520701562056

8. Gurudu SR, Fry LC, Fleischer DE, Jones BH, Trunkenbolz MR, Leighton JA: Factors contributing to patient nonattendance at open-access endoscopy. Dig Dis Sci. 2006, 51:1942-1945. 10.1007/s10620-006-9215-0

9. Laiyemo AO, Williams CD, Burnside C, et al. : Factors associated with attendance to scheduled outpatient endoscopy. Postgrad Med J. 2014, 90:571-575. 10.1136/postgradmedj-2012-131650

10. Downer SR, Meara JG, Da Costa AC: Use of SMS text messaging to improve outpatient attendance. Med J Aust. 2005, 183:366-368. 10.1136/postgradmedj-2012-131650

11. LaGanga LR, Lawrence SR: Clinic overbooking to improve patient access and increase provider productivity . Decis Sci. 2007, 38:251-276. 10.1111/j.1540-5915.2007.00158.x 